\title{
Biodegradable stents for the treatment of bowel strictures in Crohn's disease: technical results and challenges
}

Authors

Institutions
John Gásdal Karstensen ${ }^{1,2}$, Katrine Risager Christensen¹, Jørn Brynskov ${ }^{1}$, Claus Rønholt ${ }^{3}$, Peter Vilmann', Jakob Hendel ${ }^{1}$

${ }^{1}$ Gastro Unit, Division of Endoscopy, Copenhagen University Hospital Herlev, Denmark

${ }^{2}$ Gastro Unit, Division of Surgery, Copenhagen University Hospital Hvidovre, Denmark

${ }^{3}$ Gastro Unit, Division of Surgery, Copenhagen University Hospital Herlev, Denmark submitted

5. November 2015 accepted after revision 19. January 2016

\section{Bibliography \\ Dol http://dx.doi.org/ 10.1055/s-0042-101940 Endoscopy International Open 2016; 04: E296-E300 \\ (c) Georg Thieme Verlag KG Stuttgart · New York E-ISSN 2196-9736}

Corresponding author John Gásdal Karstensen, MD, PhD

Gastro Unit, Division of Endoscopy

Copenhagen University

Hospital Herlev

2730 Herlev

Denmark

john.gasdal.

karstensen.01@regionh.dk
Background and study aims: In patients with Crohn's disease, the idea of biodegradable stents for treatment of bowel strictures with limited effect of endoscopic balloon dilation is tempting and initial results have been promising. The aim of this study was to evaluate the technical and clinical success of biodegradable stents for treatment of inflamed Crohn's strictures refractory to endoscopic balloon dilatation.

Patients and methods: Consecutive patients treated with biodegradable stents due to Crohn's disease and inflamed bowel strictures refractory to endoscopic balloon dilatation were included. Technical and clinical success were evaluated.

\section{Introduction}

$\nabla$

Bowel obstruction due to intestinal stricture formation is a well-known complication of Crohn's disease $(C D)$. The recommended treatment of short strictures before surgical resection is endoscopic balloon dilation (EBD) combined with optimized medical therapy in case of significant active luminal disease [1]. However, $50 \%$ to $75 \%$ of patients experience recurrence of the stricture within 1 year after EBD [2-4]. In these patients, self-expanding metal stents (SEMS) could be a minimally invasive alternative to repeat EBD or surgery. Both covered and partially covered metal stents have been used clinically, but rather high rates of adverse events have been reported and removal of the stent within the first month after deployment is required to avoid intestinal impaction [5-7]. Biodegradable stents have recently been introduced in an attempt to overcome these drawbacks, and initial case reports and series have shown promising results with acceptable clinical results and no mucosal overgrowth [811]. However, the results from some of these studies have been criticized because they included patients naïve to EBD [12]. The aim of this study was to evaluate the feasibility and clinical
Results: Six patients were included in the study. Technical success was obtained in five patients (83\%). Clinical success was limited to one patient (20\%); failure was observed due to mucosal overgrowth $(n=2)$, stent migration $(n=1)$, and stent collapse $(n=1)$.

Conclusions: In Crohn's disease, it is technically feasible to treat bowel strictures with biodegradable stents. However, we have stopped using biodegradable stents due to lack of clinical success and side effects such as mucosal overgrowth and stent collapse.

success of biodegradable stents to treat inflamed $\mathrm{CD}$ associated strictures refractory to standard EBD.

\section{Case reports \\ $\nabla$}

\section{Patients}

Between December 2011 and February 2015, six patients with known $\mathrm{CD}$ and inflamed bowel strictures were included in the study. The median age was 51 years (range 25-60) and four were female. Three out of six strictures were located at an ileocolic anastomosis, while the remaining were located in the duodenal bulb, the sigmoid colon, and the ascending limb of a J-pouch, respectively. The patients had been treated by a median of 5.5 (range 4-7) EBDs prior to stent placement. $\bigcirc$ Table 1 summarizes patient demographics. The decision to treat the patients with biodegradable stents was made in multidisciplinary meetings. Because the stents are CE approved, this retrospective case series was not subject to approval by the local ethics committee. 


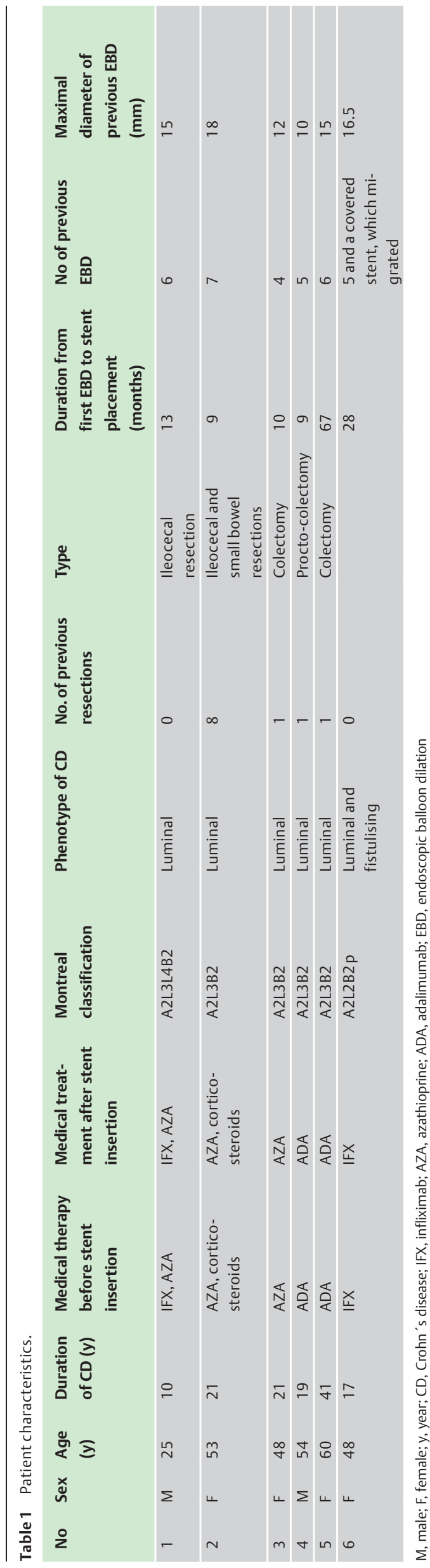

\section{Biodegradable stents}

The biodegradable stents consisted of polydioxanone monofilament, which is expected to secure the integrity and maintenance of radial force for 6 to 8 weeks before degradation (SX-ELLA BD biodegradable stent; ELLA-CS, Hradec Králové, Czech Republic) ( $\bullet$ Fig. 1). The biodegradable stents were initially designed to treat esophageal strictures and intestinal use has been limited to the left side of the colon using the same delivery device. However, a custom-made system is now available to facilitate stent deployment in the proximal colon, ileum, or duodenum. In a few previous cases the stents were placed during fluoroscopic control via an overtube (TS13140, Fujifilm, Tokyo, Japan). The length of the stents was $6 \mathrm{~cm}$ with a diameter of $18 \mathrm{~mm}$ and flares of 25 $\mathrm{mm}$. In one case a stent was custom-made for a long, narrow stricture [10].

\section{Endoscopy}

Standard gastroscopes (EG 29-i10, Pentax Medical, Tokyo, Japan) or colonoscopes (EC 38-i10 L, Pentax Medical, Tokyo, Japan) were used for stent placement in this study. Endoscopic follow-up was performed after 1 and 3 weeks. In case of suspected complications or lack of clinical success, a follow-up examination was performed within 48 hours. Technical success was defined as deployment of the stent at the desired anatomic location, while clinical success was defined as six-months relief of obstructive symptoms.

\section{Results}

\section{Technical success}

Technical success was achieved in five patients (83\%) ( $\bullet$ Table 2 ). No adverse events were registered in relation to stent deployment. In one patient with an anastomotic ileocolic stricture (Case 2), stent deployment failed because a sharp angulation of the colon made it impossible to deliver the stent via the overtube. Since this attempt, the patient has been managed with repetitive EBDs.

\section{Clinical outcome}

Clinical success was achieved in only one of five patients (20\%) and even in that individual (Case 4) the stricture did not resolve and 8 months later, EBDs were needed to avoid bowel obstruction ( $\bullet$ Table 2). The stent migrated in one patient (Case 1 ), who

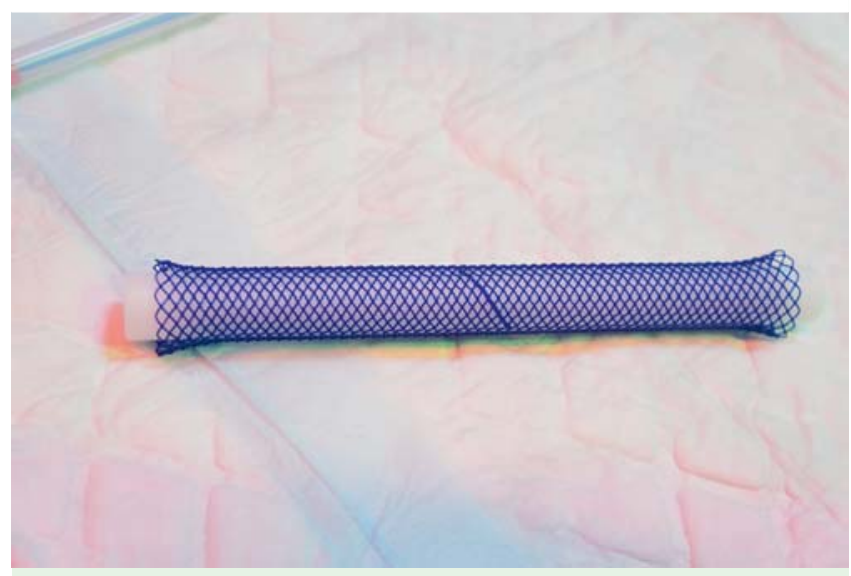

Fig. 1 A biodegradable stent consisting of polydioxanone monofilament. 


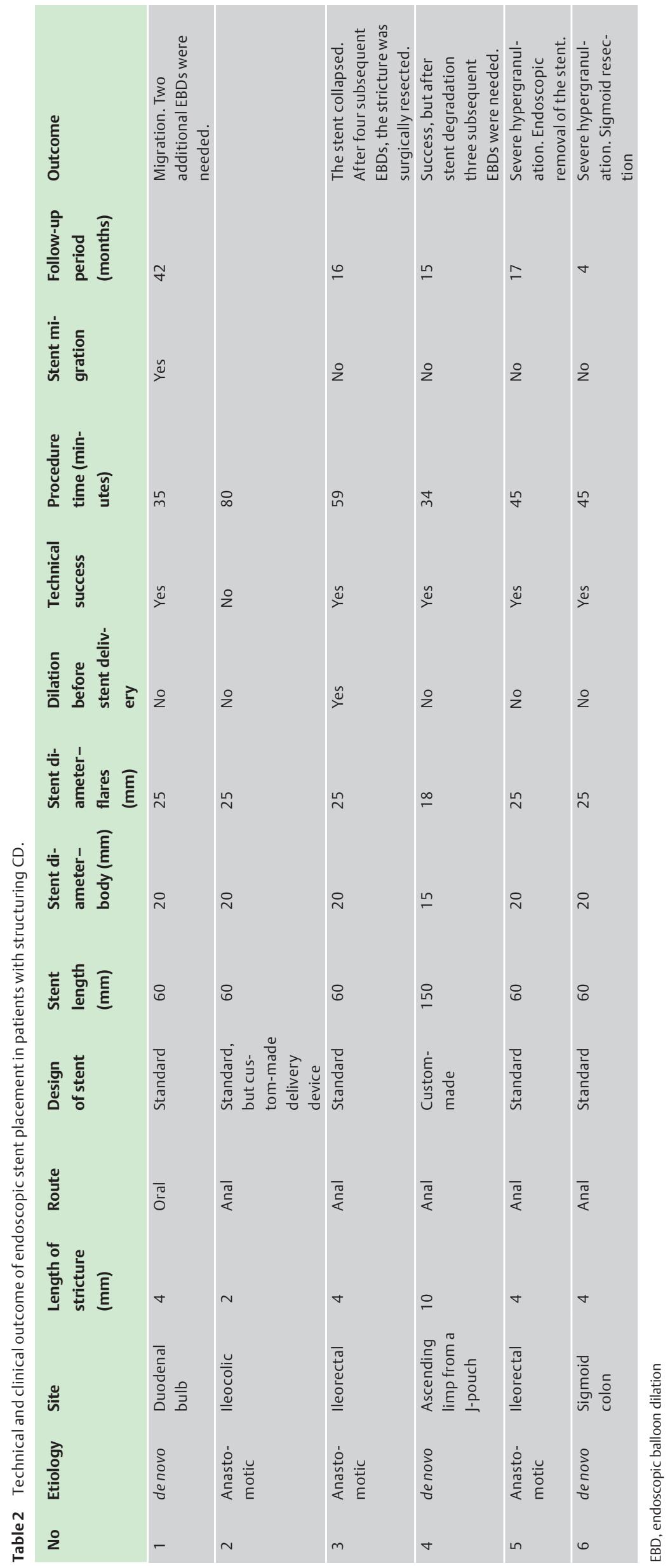




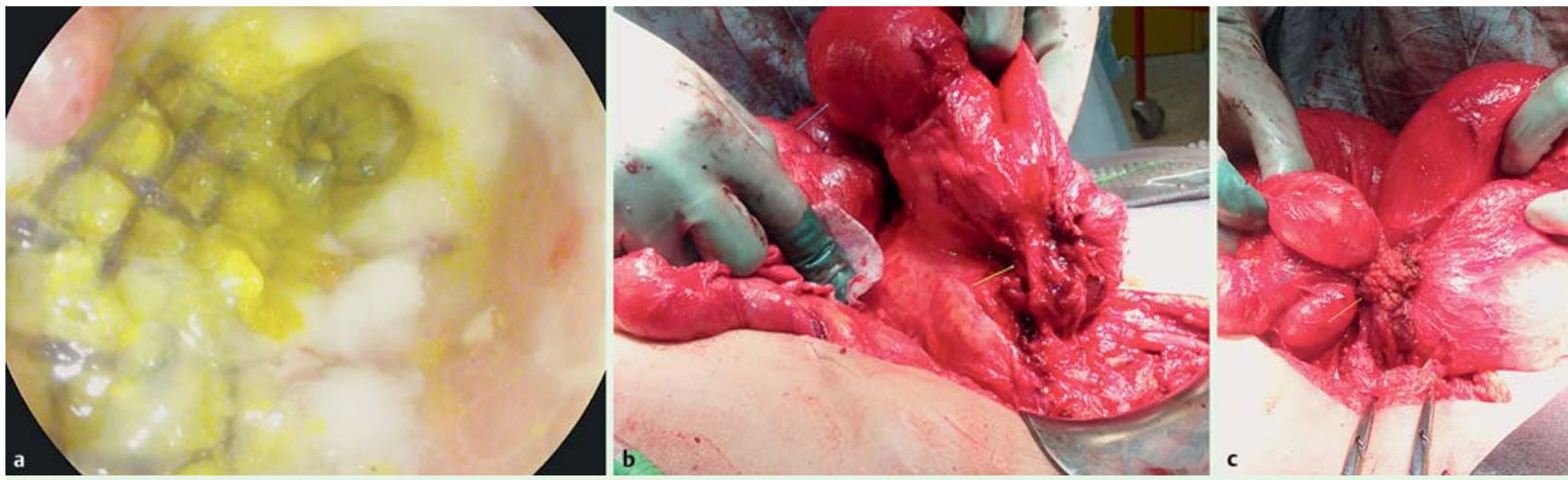

Fig. 2 a The biodegradable stent collapsed after deployment in an inflamed stricture located at the ileorectal anastomosis. $\mathbf{b}$ and $\mathbf{c}$ The patient was subsequently admitted to surgical bowel resection. The stricture was short (yellow arrows) with hypergranulation and had caused chronic prestenotic dilatation (blue arrows).

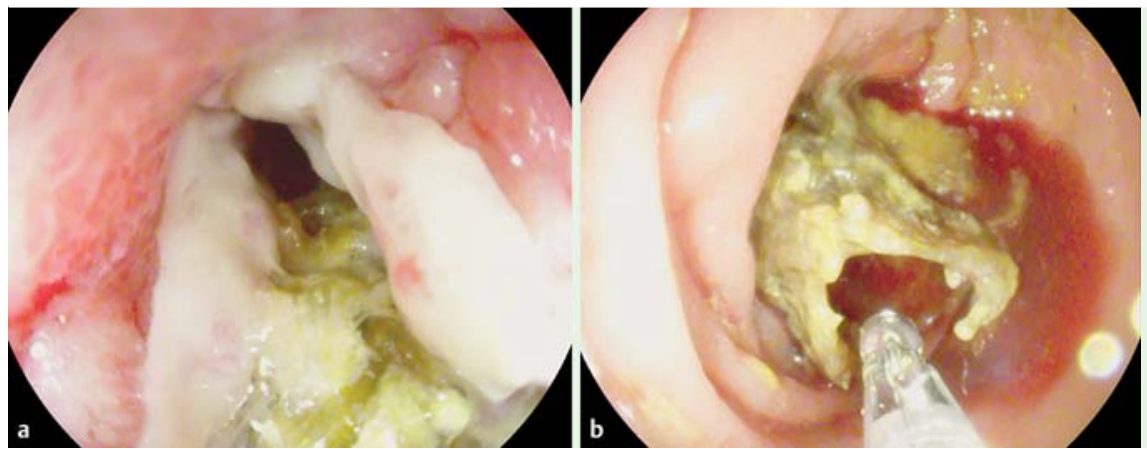

Fig. 3 a and $\mathbf{b}$ The biodegradable stent was deployed in an inflamed ileorectal stricture in a patient with $C D$, where it led to severe hypergranulation and consequently had to be removed endoscopically.

had to be managed by EBDs; however, despite the location of the stricture in the duodenal bulb, retrieval of the migrated stent was unnecessary because it degraded. In one patient (Case 3) with an inflamed anastomotic ileorectal stricture, the stent collapsed $(\bullet$ Fig. 2a). Afterward, that patient needed repetitive EBDs before finally having surgical bowel resection ( $\bullet$ Fig. 2 b and $\bullet$ Fig. 2c). In two patients (Case 5 and Case 6 ) the stents had to be removed either endoscopically ( $\bullet$ Fig. 3a and $\bullet$ Fig.3b) or by bowel resection because of severe hypergranulation ( $\bullet$ Video 1 ).

\section{Discussion}

$\nabla$

In this case series, we have shown that it is technically feasible to deploy biodegradable stents in CD strictures. However, clinical success was almost invariably limited by stent malfunction or hypergranulation.

While surgical resection or stricturoplasty traditionally have been used to treat CD strictures, EBD has now become an alternative minimally invasive approach [1]. Nevertheless, in some patients the effect of EBD is transient while in others the therapeutic may not outweigh the risk of perforation with subsequent surgery leading to a permanent stoma or short bowel syndrome. Despite a close interplay between gastroenterologists, surgeons, and endoscopists, managing this particular group of patients is challenging. Several endoscopic approaches have been suggested including sequential EBDs, local injections of steroids or TNF- $\alpha$ inhibitors, endoscopic stricture resections, or in some cases, stenting with either covered or biodegradable stents [7,13-15]. However, given the heterogeneity of the patients included in these studies, it can be difficult to gain sufficient evidence for standardization of treatment and consequently, the approach needs to be tailored on a patient-by-patient basis.

In our case series, we used biodegradable stents for treatment of both small bowel and colonic strictures with anastomotic as well as de novo origin. However, after treating six patients, the rate of clinical success was unacceptable and stent malfunction was common. Data from the initial case series using biodegradable

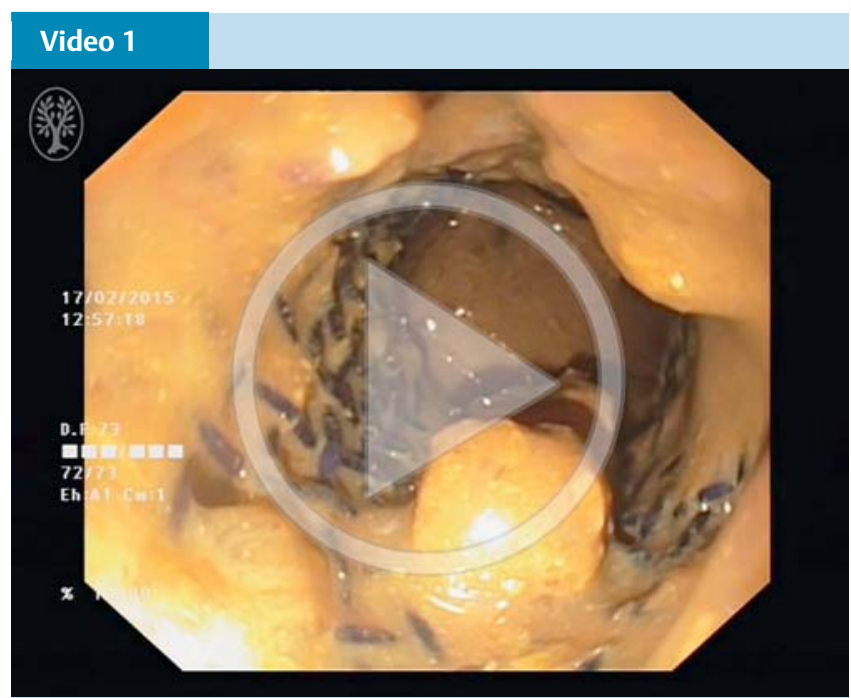

The biodegradable stent was used to treat an inflamed de novo stricture in the sigmoid colon of a patient with $\mathrm{CD}$. It caused severe hypergranulation and the patient was referred to surgery. Online content including video sequences viewable at: http://dx.doi.org/10.1055/s-0042-101940 
stents in CD strictures were promising, with clinical success rates ranging from $70 \%$ to $83 \%$ with no cases of mucosal overgrowth. Unfortunately, we were unable to reproduce these results and beside one technical failure in relation to stent deployment, we experienced two patients with severe hypergranulation, one stent migration, and one stent that collapsed [8,9]. A possible explanation could be that the patients included in our case study had received multiple EBDs due to refractory stricture formation and all of them had symptoms of bowel obstruction. This differs from the largest case series, where $36 \%$ were naive to EBD and only $45 \%$ had obstructive symptoms. Based on our experience, we have now stopped using this treatment modality and if endoscopic stenting is required, we will use SEMSs. Furthermore, because case series are often influenced by publication bias, we find that it is relevant to report our negative results.

In conclusion, the idea of biodegradable stents is tempting and deployment is technically feasible, but due to limited clinical success, we have stopped using this treatment modality until the stents can be modified to address the problems described in this case series.

\section{Competing interests: None}

\section{Acknowledgements}

$\nabla$

The Foundation of Arvid Nilsson supported this work.

\section{References}

1 Dignass A, Van Assche G, Lindsay JO et al. The second European evidence-based Consensus on the diagnosis and management of Crohn's disease: Current management. J Crohn's Colitis 2010; 4: 28-62

2 Thienpont C, D'Hoore A, Vermeire $S$ et al. Long-term outcome of endoscopic dilatation in patients with Crohn's disease is not affected by disease activity or medical therapy. Gut 2010; 59: 320-324
3 Karstensen JG, Hendel J, Vilmann P. Endoscopic balloon dilatation for Crohn's strictures of the gastrointestinal tract is feasible. Dan Med J 2012; 59: A4471

4 Ferlitsch A, Reinisch $W$, Puspok $A$ et al. Safety and efficacy of endoscopic balloon dilation for treatment of Crohn's disease strictures. Endoscopy 2006; 38: $483-487$

5 Attar A, Maunoury $V$, Vahedi $K$ et al. Safety and efficacy of extractible self-expandable metal stents in the treatment of Crohn's disease intestinal strictures: a prospective pilot study. Inflamm Bowel Dis 2012; 18: $1849-1854$

6 Branche J, Attar A, Vernier-Massouille G et al. Extractible self-expandable metal stent in the treatment of Crohn's disease anastomotic strictures. Endoscopy 2012; 44 Suppl 2 UCTN: E325 -E326

7 Loras C, Perez-Roldan F, Gornals JB et al. Endoscopic treatment with self-expanding metal stents for Crohn's disease strictures. Aliment Pharmacol Ther 2012; 36: 833-839

8 Rejchrt S, Kopacova M, BrozikJ et al. Biodegradable stents for the treatment of benign stenoses of the small and large intestines. Endoscopy 2011; 43: 911 -917

9 Roldan PF, Gonzalez CarroP, Villafanez GarciaMC et al. Usefulness of biodegradable polydioxanone stents in the treatment of postsurgical colorectal strictures and fistulas. Endoscopy 2012; 44: 297-300

10 Karstensen JG, Vilmann P, Hendel J. Successful endoscopic treatment of a 12-cm small-bowel Crohn stricture with a custom-made biodegradable stent. Endoscopy 2014; 46: E227-228

11 Krokidis M, Burke C, Spiliopoulos $S$ et al. The use of biodegradable stents in malignant oesophageal strictures for the treatment of dysphagia before neoadjuvant treatment or radical radiotherapy: a feasibility study. Cardiol Intervent Radiol 2013; 36: 1047-1054

12 Saritas $U$, Ustundag $Y$. Biodegradable stents: another big step in the field of non-surgical therapy for fibrostenotic Crohn's disease. Endoscopy 2012; 44: 435 ; author reply 436

13 East JE, Brooker JC, Rutter MD et al. A pilot study of intrastricture steroid versus placebo injection after balloon dilatation of Crohn's strictures. Clinical gastroenterology and hepatology : the official clinical practice. J Am Gastrointest Assoc 2007; 5: 1065-1069

14 Hendel J, Karstensen JG, Vilmann P. Serial intralesional injections of infliximab in small bowel Crohn's strictures are feasible and might lower inflammation. United European Gastroenterol J 2014; 2: 406-412

15 Paine $E$, Shen $B$. Endoscopic therapy in inflammatory bowel diseases (with videos). Gastrointest Endosc 2013; 78: 819-835 